\title{
SELF-SELECTION INTO CORRUPTION: EVIDENCE FROM THE LAB
}

\author{
Pablo Brassiolo \\ Ricardo Estrada \\ Gustavo Fajardo \\ Juan F. Vargas
}

\section{LATIN AMERICAN AND THE CARIBBEAN ECONOMIC ASSOCIATION}

May 2020

The views expressed herein are those of the authors and do not necessarily reflect the views of the Latin American and the Caribbean Economic Association. Research published in this series may include views on policy, but LACEA takes no institutional policy positions.

LACEA working papers are circulated for discussion and comment purposes. Citation of such a paper should account for its provisional character. A revised version may be available directly from the author.

(C) 2020 by Pablo Brassiolo, Ricardo Estrada, Gustavo Fajardo and Juan F. Vargas. All rights reserved. Short sections of text, not to exceed two paragraphs, may be quoted without explicit permission provided that full credit, including (C) notice, is given to the source. 
LACEA WORKING PAPER SERIES No. 0045 May 2020

Self-Selection into Corruption: Evidence from the Lab

Pablo Brassiolo

CAF-Development Bank of Latin America

pbrassiolo@caf.com

Ricardo Estrada

CAF-Development Bank of Latin America

restrada@caf.com

Gustavo Fajardo

CAF-Development Bank of Latin America

gfajardo@caf.com

Juan F. Vargas

School of Economics, Universidad del Rosario

juan.vargas@urosario.edu.co

\section{ABSTRACT}

We study whether opportunities to extract rents in a job affect the type of individuals who are attracted to it in terms of their underlying integrity. We do so in a laboratory experiment in which participants choose between two contracts that involve different tasks. We experimentally introduce the possibility of graft in one of them and study the sorting of subjects across contracts based on an incentivized measure of honesty. We find that the corruptible contract changes the composition of subjects because it attracts the most dishonest individuals and repels the most honest ones. In addition, we observe extensive graft when the opportunity is available. We introduce a double randomization strategy to disentangle the extent of which stealing responds to the aforementioned negative selection or to pure incentives (net of selection). We find that, in this setting, selection is the main driver of graft. Our results have clear policy implications to curb corruption.

JEL Classification: C91, D73, M5.

Keywords: Corruption, selection, rent extraction opportunities, personnel economics.

\section{ACKNOWLEDGEMENTS AND FINANCIAL DISCLOSURE}

We thank Mariana Blanco, Jorge Gallego, Cesar Mantilla, Mauricio Rodriguez and seminar participants from the Bogota Experimental and Behavioral Economics Seminar (BEBES), Universidad del Rosario and CAF-Development Bank of Latin America. We are indebted to the

Rosario Experimental Economics Lab (REBEL) and especially to Daniel Gomez for support and logistics. Cynthia Marchioni provided excellent research assistance. This study is registered in the AEA RCT Registry and the unique identifying number is: AEARCTR-0003877. 


\section{Introduction}

Corruption is one of the most pernicious problems of society (Svensson, 2005; Olken, 2007). An important strand of the literature argues that its main driver has to do with the institutional features that shape the decisions of incumbent public officials to engage in illicit behavior. Under this view, corruption responds to incentives and to lack of monitoring Olken and Pande, 2012). However, incentives might also shape corruption by affecting who joins the public sector in the first place. Notably, the potential to extract rents in a job might attract individuals with lower integrity standards, who would profit from the available corruption opportunities (Besley, 2005).

Hanna and Wang (2017) use a measure of dishonesty elicited in an incentivized laboratory task and find that, in India, more dishonest students are more interested in public sector jobs.1 Using a similar measure of dishonesty among Danish students, Barfort et al. (2019) find that, in sharp contrast to the Indian case, it is the more honest students who prefer public sector positions. Taken together, these studies suggest that self-selection into the public sector is a function of the existent (or perceived) corruption opportunities. However, to the best of our knowledge, there is no previous work that provides causal estimates of this relationship. This gap is probably due to the lack of information on integrity and corrupt behavior at the individual level, as well as to the difficulty in finding exogenous variation in the availability of jobs with and without rent extraction opportunities.

In this paper, we address both of these issues in a laboratory experiment designed to study the relationship between the opportunities to extract rents in a job and the integrity of the individuals who are attracted to it. In addition, our design allows us to explore how much of the actual rent extraction is explained by self-selection vis- $\tilde{A}$-vis pure incentives (net of selection). In the experiment, subjects have to choose between two contracts that are intended to emulate private and public sector job characteristics. The "private contract" entails a real-effort task and subjects receive a payment with both a fixed and a performancebased component. The "public contract" involves the allocation of a monetary fund among five real NGOs and in exchange subjects receive a fixed payment.

Only the public contract varies across the randomly assigned treatment and control groups. Subjects in the treatment (control) group face a monetary fund composed of real (toy) banknotes. All other characteristics remain the same, including the guarantee of secrecy regarding how much each participant assigns to each NGO. This secrecy allows participants

\footnotetext{
${ }^{1}$ In a similar vein, Banerjee, Baul, and Rosenblat (2015) find that students enrolled in programs preparing for India's national public sector exam are more prone to corruption than MBA students.
} 
who choose the public contract to keep some banknotes for themselves. In this way, we exogenously introduce the possibility of extracting monetary rents in the treatment group, which allows us to study how rent-extraction opportunities affect self selection into a ("public sector") job.

Selection is studied in terms of the underlying honesty of the subjects. To that end, at the beginning of each session and prior to the job-choice task, subjects perform a validated and incentivized dice task that determines their propensity to cheat (as in Hanna and Wang, 2017). In addition, we collect information on subjects' socio-demographic characteristics as well as personality traits and measures of risk attitude and prosocial motivation.

We find that, relative to the control, the possibility of extracting rents changes both the number and the type of subjects who self-select into the public contract. The proportion falls by 10 percentage points, a $32 \%$ decrease with respect to the control mean. Crucially, this net fall is the result of a compositional change in terms of baseline integrity. While subjects with a higher propensity to cheat are more likely to select the public contract when rent extraction is possible, relatively more honest individuals become less attracted to the job. While the former is perhaps more intuitive, we interpret the negative selection of the honest as suggestive evidence that they value reputation or suffer a moral cost from being part of a corrupt environment (Bénabou and Tirole, 2011).

We then turn to study actual rent extraction. In the treatment group, when the fund to be distributed among the NGOs is made up of real cash, 7 out of 10 subjects keep some money for themselves. This is on top of the fixed payment they are entitled to for choosing the public contract. In the control group, less than $5 \%$ of subjects keep any toy banknote. In the treatment group, the proportion of the funds that is taken away from the money that the experimenter will donate to the NGOs is $45 \%$. In the control group the equivalent figure is less than 4\%. Since the reduction in donations is due to the use of cash instead of tokens, we interpret this evidence as graft. Moreover, as expected, we find that graft is higher among people with lower levels of baseline integrity (as measured by the dice game).

Why does the use of real-as opposed to toy-money promote graft? There are two main potential mechanisms (Olken and Pande, 2012): selection and pure incentives (net of selection). In most contexts, it is impossible to disentangle among them because of the fact that the same incentives that affect on-the-job performance also shape selection into the job. To overcome this, one could randomly assign different incentives before and after self-selection has taken place. Such a 'double randomization' strategy would result in: i) individuals who face equal incentives when choosing a job but different incentives once on 
the job, and ii) individuals who face the same incentives on the job but faced different ones at the moment of selection. The relative empirical importance of pure incentives (selection) can be identified from the first (second) group.

We implement this by introducing a second stage of randomization in our experiment. In it, we consider the individuals in the control group, who self-selected into the token version of the public contract (without rent extraction opportunities) and, after they made that choice, we reassign a random subset of them to play the cash-based version. In this way, we exogenously introduce the opportunity to obtain rents among individuals who self-selected to a job without this possibility. This experimental group allows us to isolate the pure incentives channel. Likewise, we can parse out the selection channel using the individuals who self-selected into different versions of the public contract but ex-post faced the same opportunities for graft. Based on this strategy, our second main result is that the bulk of the observed graft is driven by self-selection.

Summing up, we show that the expectation of rents extraction in a job not only attracts the more dishonest individuals but also repeals the relatively honest, thus generating a compositional effect in the job selection stage that hampers integrity. Not surprisingly, we also find that rent extraction opportunities do translate into graft. However, using a double randomization design, we find that this behavior is explained by selection, with negligible explanatory power of the pure incentives mechanism, at least given our experimental parameters ${ }^{2}$

Our paper is closely related to the recent literature on the link between corruption and self-selection to the public sector (Hanna and Wang 2017; Barfort et al. 2019). Our contribution to this literature is twofold. First, we present the first estimates of the causal effect of graft opportunities on the integrity of those who self-select to a task ${ }^{3}$ Second, we show that the selection of low-integrity individuals can be a significant driver of actual corruption, above and beyond posterior incentives that may become apparent after the selection stage.

Our findings also speak to a the general literature on personnel economics of the state that is concerned with estimating the effects of incentives on officials' performance (see a review in Finan et al. 2017). A general challenge faced by this literature is that the features

\footnotetext{
${ }^{2}$ To be sure, this does not imply that the pure incentives channel is irrelevant to curbing corruption, especially in contexts of high stakes. Instead, we interpret our results as evidence of the importance of the selection channel, which implies that to assess the aggregate effect of a policy on corruption, one must pay attention to both channels.

${ }^{3}$ This is connected to Dal Bo, Finan, and Rossi (2013) and Deserranno (2019), who document, respectively, how wages and career incentives affect the attributes of those who join the public sector. We show that the availability of rents is another important factor that might shape entry into the public sector.
} 
of the job that shape the incentives of employees are the same ones that shape employees' selection into that position in the first place. Consequently, it is almost impossible to separate the effect of selection to that of pure incentives in a given real-world context. 4 The double randomization strategy of our research design allows us to address this issue in a controlled lab setting. Our results are consistent with those in Ashraf, Bandiera, and Lee $(2018)$, who use experimental variation in the recruitment of health care workers in Zambia to show that selection affects job performance.

On the methodological side, our experimental design constitutes a novel way to study corruption in the lab. There are three important features in our design. First, in addition to the actual behavior of subjects under a specific task, we study the actual choice that subjects make among different tasks. Second, the design allows us to obtain a behavioral measure of corruption that is free from framing effects (Abbink and Serra, 2012). We do this by leaving it to the subjects to deduce that they can extract money from the game without ever introducing that possibility explicitly. Third, and most importantly, we use a double randomization strategy to identify the effect of selection on corruption, which has not received much attention in the existing experimental literature.

Whether graft (or any other form of corruption) is driven by selection or incentives has important policy implications. If selection is most important, anti-corruption measures should emphasize the mechanisms to recruit, promote, and dismiss officials. But if incentives-net of selection-are the main explanation, efforts should be directed toward the administrative rules and protocols that govern the work of public officials. The results of this paper are relevant for recruitment and personnel policies in sectors where positions have-or are perceived to have-some discretion to obtain personal rents (importantly, for example, the public sector in developing countries). The results are also important to understand the process that govern sectors where corruption is perceived to be widespread.

The rest of the paper is organized as follows: Section 2 elaborates on the experimental design and the implementation of the experiment, Section 3 describes the empirical analysis, Section 4 presents and discusses the results, and Section 5 concludes.

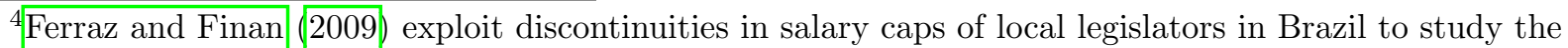
effect of higher wages on political performance. They find that performance increases mainly due to the effect of wages on the selection of better candidates. 


\section{Experimental Design}

\subsection{Recruitment, assignment and balance}

We recruited 398 undergraduate students from Universidad del Rosario, a private university in Bogota, by email. Students interested in participating in the study had to answer a short questionnaire, that we used to stratify the recruitment into experimental sessions in ORSEE. We stratified in terms of gender, major (separating Economics and Applied Math vs. all other subjects) and the answer to the question of whether the student was more inclined to, upon graduation, choose a public sector or a private sector job. Based on these individual characteristics, we randomly assigned individuals within each stratum to one of the session types. We then randomized each one of the following three treatments across sessions, and conducted a total of 15 sessions ( 5 per treatment) with an average of 25 participants in each:

- G1: Participants are offered the private contract and the token-based public contract, and they play whichever they choose.

- G2: Participants are offered the private contract and the cash-based public contract, and they play whichever they choose.

- G3: Participants are offered the private contract and the token-based public contract. Participants who chose the public contract are reassigned to play the cash-based one.

Section 2.3 provides details on each treatment. Table 1 shows descriptive statistics and the balance of covariates between the three experimental groups. Differences between groups are small and largely statistically insignificant, both for the stratification variables and for a large set of additional characteristics collected at the beginning of the experiment (see section 2.2. 6 out of 10 subjects are women and we have the same proportion of subjects from a high income socioeconomic stratum (the study is in a private elite university) and who report having preferences for a public sector job upon graduation. A third of them studies a quantitative major (either economics or applied math).

\subsection{Sessions}

The experimental sessions had three stages. In the first stage, participants filled out a survey questionnaire providing socioeconomic, demographic, and schooling information. The survey also included questions to elicit values and preferences on several political issues and measures of risk aversion, prosocial motivation, and the Big Five personality traits.

Most importantly, at this stage, we also elicited an experimental measure of dishonesty 
for each individual based on a dice task first proposed by Fischbacher and Föllmi-Heusi (2013) and modified by Hanna and Wang (2017) for obtaining an individual-level measure. In it, we asked participants to privately roll a dice 40 times and record the result of each roll in their workstation. For this task, subjects received a monetary payment equivalent to $\operatorname{COP} \$ 75(\approx$ US $\$ 0.024)$ times the total number of points reported for the 40 dice rolls. This payoff structure creates an incentive to report higher values than those obtained, which is possible because the dice is rolled privately. A reported sum of 140 points (the expected value after 40 rolls without cheating) entails a payoff of $\operatorname{COP} \$ 10,500(\approx \mathrm{US} \$ 3.40$ ).

In the second stage, individuals were presented with and asked to choose between two contracts designed to capture stylized characteristics of private and public sector jobs. A contract consisted on a set of instructions for carrying out a task and an associated payment. By choosing one contract, individuals decide to perform the associated task and receive the corresponding payment, foregoing the alternative 5

In the "private contract", the task was to solve as many sums of five randomly generated two-digit numbers as possible in two minutes. The participants who chose this contract were offered a fixed amount of $\mathrm{COP} \$ 10,000(\approx \mathrm{US} \$ 3.20)$ plus a variable payment of $\mathrm{COP} \$ 1,500$ $(\approx$ US\$0.48) for each correct sum. Incorrect answers did not entail any loss.

In the "public contract", the task consisted on distributing a COP $\$ 14,000(\approx \mathrm{US} \$ 4.50)$ monetary fund among five real NGOs. Subjects who chose this contract received five empty envelopes labeled with the names of the NGOs and a brief description of the mission and activities of these organizations. An additional envelope labeled 'Payment' was received with the fixed payment $(\mathrm{COP} \$ 12,000)$ offered to participants to perform this task. After participants had privately decided upon the distribution of the monetary fund among the NGOs, they had to deposit the five envelopes (even if some were empty) in a common urn placed in the lab and place their payment envelope inside their bag/backpack/belongings. ${ }^{6}$

In the third and final stage, participants performed the task corresponding to the contract of their choice and received their payment. First, public contract participants received their task materials, including the envelope with their payment as well as a brief explanation of the mission and activities of each of the five NGOs (presented on their computer screen). Then, everyone in the room started working on their task (either funds allocation or sums solving). After five minutes, public contract participants left the NGO envelopes

\footnotetext{
${ }^{5}$ The "public" and "private" contract framing was not used in the experiment. The private (public) contract was called contract A (B) in the instructions.

${ }^{6}$ Subjects were informed that within four weeks from the session, the experimentalist would transfer to each NGO the total amount donated. They could opt-in to receive an electronic copy of the transfer slip.
} 
in the urn and received the payment associated to the dice task just before leaving the lab. Finally, private contract participants received their total earnings (corresponding to the dice game as well as the fixed and variable components of their payment).

\section{$2.3 \quad$ Treatments}

Crucially, there are two versions of the public contract: a cash-based one (treatment) and a token-based one (control). The only difference between these is that in the cash-based version, the monetary fund comes in the form of seven COP $\$ 2,000$ legal tender banknotes, while in the token-based version the fund is made of seven toy banknotes, each representing the same face value as the legal ones. We randomly assigned experimental sessions to be offered one of those two versions.

Key to our identification strategy, the cash-based contract of the treatment group introduced opportunities for graft by creating actual monetary incentives to keep part of the NGOs fund. The token-based one did not entail the same incentive (above and beyond the negligible value of a toy banknote). Other than this, there were no differences between treatment and control: the size of the fund, the complexity of the task, and the amount of discretion were constant across both versions. Importantly, the alternative (private) contract was also equal for both groups.7

As specified in our pre-analysis plan, upon reading the instructions for the public contract, participants who chose the public contract could infer that leaving the room with some (or all) of the bills was a distinct possibility, even though this behavior is not suggested at any point. The instructions explicitly stated that no one in the room will be able to observe their fund allocation decision. This statement is credible to the participants because they worked in individual stations with well-defined cubicle partitions, where nobody could observe how many bills they put in the envelopes that they then sealed and placed in the urn before leaving the room.

Instead of relying in some form of experimenter's demand, we stress the secrecy of the allocation decision to ensure that any subject wishing to keep for herself a fraction of the fund would expect to do so without being caught. To avoid priming subjects about graft being a relevant outcome of the experiment, we justified the secrecy of the decision by including NGOs with non-uncontroversial missions (especially within the Colombian context). In

\footnotetext{
${ }^{7}$ The instructions clearly stated that the payment for the public contract was COP $\$ 12,000$, avoiding the concern that individuals may felt legitimately entitled to the NGOs monetary fund. This allows us to confidently interpret as graft any appropriation of money from the fund by a participant in the treatment group.
} 
particular, we included pro-life and pro-choice NGOs as well as NGOs representing former combatants or else representing victims of the 5-decade long Colombian armed conflict.

Notice that, when the participants finally perform the fund distribution task, the experimenter can observe whether subjects allocated the entire or just a fraction of it to the NGO fund. This allows us to infer if subjects are keeping money for themselves beyond their task-specific compensation. This is our measure of individual-level graft 8 While we can characterize both the extensive and the intensive margin of graft in terms of individual characteristics (including our baseline measure of honesty), in principle we cannot test the empirical relevance of the two main mechanisms of corruption highlighted by the literature: selection and incentives. The first would suggest that rent extraction opportunities generate graft because they attract more dishonest individuals. Instead, the pure incentives channel implies that individuals respond to rent extraction opportunities above and beyond their underlying integrity. While these two mechanism are clearly complementary, empirically disentangling the relative importance of each of them is extremely challenging with observational data.

To separate the selection and the pure-incentives channels of graft, after participants made their choice between the two contracts (stage 2 in section 2.2), we introduced a second randomized treatment. In particular, following Karlan and Zinman (2009), in a random half of the sessions offering the token-based public contract (i.e. in the initial, control group) we reassigned all participants who chose that contract to play the cash-based public contract. To that end, after the contract choice took place, the experimenter publicly announced that, instead of tokens, the monetary fund will be made up of real banknotes.

Figure 1 offers a description of the timeline of events in each treatment-type of session.

\section{Empirical Analysis}

\subsection{Contract choice}

As specified in the pre-analysis plan, our first main outcome of interest is whether the choice between the public and the private contract differs (in terms of the proportion and the type of individuals) depending on the type of public contract offered. That is, whether the monetary

\footnotetext{
${ }^{8}$ We marked the five NGO envelopes used to distribute the monetary fund with a unique pattern that allowed us to identify how much each participant gave to each organization and, by residual, how much of the total NGO fund the subject kept. Importantly, we could only identify the session/working station ID to link graft with the baseline survey and measure of honesty, but we could not track that allocation decision back to participants' names or personal information. This protocol was approved and overseen by Universidad del Rosario's IRB, under the approval number DVO005-175-CS110.
} 
fund to distribute among NGOs was composed by real money or else by tokens.

To test the effect of the type of public contract offered on the number of individuals who choose the public contract, we index subjects by $i$ and sessions by $s$ and estimate the following regression model on the full sample of subjects:

$$
Y_{i s}=\alpha+\beta \text { Cash } \text { based }_{s}+\delta^{\prime} X_{i s}+\gamma^{\prime} S_{i s}+\epsilon_{i s}
$$

where $Y_{i s}$ is a dummy variable that equals one if subject $i$ of session $s$ chose the public contract and 0 she chose the private contract. Our treatment variable is Cash - based $d_{s}$ and takes value 1 if session $s$ was (randomly) assigned to offering the cash-based public contract. This implies that, for this set of results, individuals from sessions G1 and G3 represent the control group (Cash - based $=0)$, while individuals from G2 sessions are treated (Cash - based=1). $X_{i s}$ is a vector of individual controls other than the variables used for stratification, which are captured by $S_{i s}$.

Our coefficient of interest, $\beta$, captures the treatment effect of being offered the public cash contract on the probability of choosing the public contract. Because of the random assignment, we interpret this as the causal effect of introducing graft opportunities in a job on the probability that individuals self-select into it.

The introduction of opportunities for graft should make the public contract relatively more attractive to more dishonest individuals. This implies that, beyond its effect on the number of subjects who choose it (which we identify by estimating equation 1), the cashbased contract would have consequences on the composition of individuals who self-select into it. We explore this by estimating equation (2), where $D_{i s}$ is the total number of points reported by subject $i$ in session $s$ for the dice task. Since this variable increases with the probability of dishonesty, we expect the coefficient of the interaction term $\left(\beta_{3}\right)$ to be positive.

$$
Y_{i s}=\alpha+\beta_{1} \text { Cash-based }_{s}+\beta_{2} D_{i s}+\beta_{3} \text { Cash-based } \times D_{i s}+\delta^{\prime} X_{i s}+\gamma^{\prime} S_{i s}+\mu_{i s}
$$

Alternatively, and for an easier interpretation, we also divide $D$ into its empirical terciles, and interact the tercile-specific dummies with the Cash - based indicator. This specification is shown in equation (3), where $I_{j}$ takes value 1 for observations in the $j^{\text {th }}$ tercile of the empirical distribution of total points in the dice game. 


$$
\begin{aligned}
& Y_{i s}=\alpha+\phi \text { Cash }_{\text {-based }}+\sum_{j=2}^{3} \theta_{j}\left(I_{j}=1\right)+\sum_{j=2}^{3} \beta_{j}\left(I_{j}=1\right) \text { Cash }_{\text {-based }} \\
& +\delta^{\prime} X_{i s}+\gamma^{\prime} S_{i s}+\rho_{i s}
\end{aligned}
$$

where the indicator of the first tercile is omitted to avoid perfect collinearity and thus the coefficients $\theta_{j}$ and $\beta_{j}$ should be interpreted relative to the omitted tercile.

We also assess if there are composition effects on dimensions other than honesty. We do so by estimating equation 2 but replacing our measure of honesty with variables that capture risk attitudes, pro-sociality, and Big Five personality traits.

\subsection{Graft}

We also study actual graft from the information we gather on individuals' allocation of the NGOs monetary fund. We capture rent extraction in the extensive margin and in the intensive margin. For the former we construct a dummy that equals one if the total amount allocated to the NGOs is smaller than the value of the fund. For the latter we compute the share of the fund value that is kept by each subject. Notice that these outcomes are defined only for subjects who choose the public contract.

We first note that, interestingly, neither of these variables take the value zero for the token-based version of the public contract. Reassuringly, however, the figures are rather small. Less that 5 percent of the participants of sessions assigned to the token-based public contract kept at least one toy banknote, and the average value kept is less than 4 percent of the total value of the fund. This could have happen for two reason. It may be that a very small number of participants actually forgot to introduce all the tokens into the NGO envelopes, or it may be that toy banknotes did represent some small positive utility to very few participants. Whatever the reason, this gives us a baseline level of monetary fund loss that is not explained by rent extraction opportunities. In any case, we interpret as graft any positive change relative to this baseline level that arises in the cash-based public contract.

To capture this, we re-estimate equation 1 using as outcomes the described measures of rent extraction in the extensive and in the intensive margin, focusing on the sample of subjects who chose the public contract. This allows us to measure how the introduction of opportunities for graft changed the allocation decisions regarding the monetary fund. That is, it allows us to gauge the extent of graft in our experiment. 
We limit this analysis to subjects from groups G1 and G2, who not only played different versions of the public contract task (one with tokes and the other one with cash), but who first self-selected into these different tasks. That is, we abstract from individuals in group G3 since the treatment variable (Cash-based in equation 1) is not well defined for them in that they did not play the same version of the contract that they chose.

This strategy, however, gives us no hint regarding the channels that explain the incidence of graft. To see this note that, because subjects from groups G1 and G2 undertook the contract tasks they first chose to do, any observed graft may simultaneously be driven by selection and by incentives (net of selection).

\subsection{Separating selection and incentives}

G3 sessions are designed precisely to disentangle selection and incentives. In it, subjects who self-selected into the token-based version of the public contract were randomly reassigned into the cash-based version. In this context, it is noteworthy that the comparison between the behavior of subjects from G1 and from G3 is informative about the pure incentives channel: both groups are equally self-selected (so there are no differences in the composition of honesty), but they randomly end up actually undertaking different versions of the public contract (one with rent extraction opportunities and the other one without them).

On the other hand, the comparison between G2 and G3 is informative about the selection channel: the groups are differently self-selected (which potentially affects the honestycomposition of the groups), but they randomly end up playing under the same conditions.

Following Karlan and Zinman (2009), we use this double randomization strategy to separate both channels. To that end, we estimate equation 4 for all individuals who chose the public contract in all the sessions. There, the outcome $Y_{i s}$ is either measure of the allocation decision of the monetary fund (i.e. the extensive or the intensive margin of graft). In addition, Cash-based offered takes the value 1 if subject $i$ was in a session in which the cash-based public contract was offered (and 0 if the token-based contract was offered), and Cash-based played equals 1 for subjects in sessions who played the cash-based public contract task, either by choice or reassignment (and 0 if the token-based was played).

$$
Y_{i s}=\alpha+\beta_{1} \text { Cash-based offered } \text { of }_{s}+\beta_{2} \text { Cash-based played } \text { bl }_{s}+\delta^{\prime} X_{i}+\gamma^{\prime} S_{i}+\eta_{i s}
$$

In this specification, $\beta_{1}$ captures the change in allocation decisions that comes exclu- 
sively through changes in the composition of individuals making those decisions. It thus captures the selection channel. In turn, $\beta_{2}$ captures the effect of the incentives channel, controlling for the changes in composition due to differential selection. While we would expect both effects to be weakly positive, we are more interested in their relative magnitude.

\section{Results}

\subsection{Baseline honesty}

Our subjects show high levels of cheating according to our experimental measure: they report an average of 158 points obtained from 40 private dice rolls. This figure is 13 percent larger than the expected value of that variable. We can also compute the proportion of individuals who report point totals with a very low probability of occurrence. In our sample, 30 percent of participants report a total of points equal to or greater than 165, which is the 99th percentile of the theoretical distribution of 40 rolls of a fair die 9

Figure 2 plots both the empirical distribution of points in the dice task from our sample and a simulated distribution. The former is clearly displaced to the right of the latter. The empirical distribution shows a noticeable spike in the value 240, which is the maximum of the range of possible values of the variable 10

\subsection{Contract choice}

Table 2 reports our estimates of the effect of the existence of opportunities for rent extraction on the probability of choosing the public contract. Recall that, to that end, we estimate equation 1. All the columns control for the stratification variables: gender, an indicator of preference for a public sector job graduation, and a dummy of whether the subject is enrolled in a quantitative major. Additional covariates are introduced in Columns 2 and thereafter. These include age, GPA, socioeconomic status, validated measures of risk preference and pro-sociality, the Big five personality traits, and the recorded score in the dice task. Because of its importance, we report the estimated coefficient of this control.

Column 3 and the subsequent columns further investigate whether the introduction of rent extraction opportunities make the public contract more attractive to the relatively more

\footnotetext{
${ }^{9}$ Reassuringly, these numbers are very close to those obtained by Hanna and Wang (2017) in their sample of Indian students in spite of the potential large differences across the two samples in terms of individual characteristics. They find that the average report is 14 percent higher than the expected value, and 34 percent of the reports are above the 99th percentile of the corresponding theoretical distribution.

${ }^{10}$ Eight individuals (approximately 2 percent of the sample) reported a six on every roll of the die.
} 
dishonest individuals. To that end in Column 3 we estimate equation 2 where the indicator of whether the public contract is cash based is interacted with the reported total number of points obtained in the dice task. Column 4 repeats the same exercise but instead of using the continuous measure of reported dice points, it uses a dummy variable that captures whether the reported figure is unlikely (i.e. above the $99^{t h}$ percentile of the theoretical distribution). Finally, Column 5 reports the results from estimating equation 3 , where we interact the cashbased public contract indicator with the terciles of the empirical distribution of reported dice points.

We find that, the introduction of graft opportunities reduces the likelihood of choosing the public contract by 10 percentage points (Column 1). The magnitude and significance of this effect are robust to the introduction of a large set of individual controls other than the stratification variables -and including our elicited measure of honesty-(Column 2). This effect is economically large: it implies that the average interest in the public contract falls by about one-third with respect to an identical version of it in which no rents can be extracted.

Moreover, we find that the introduction of graft opportunities in the public contract alienates the most honest individuals while attracting those with a higher propensity to cheat. Column 3 shows that the more dishonest subjects are (according to the total reported points from the dice task), the more likely they are to choose the public contract when they anticipate the opportunity of graft.

To facilitate the interpretation of the estimated coefficients, the variable that captures the reported dice points is standardized. This implies that, relative to the control (where the NGOs fund is allocated with tokens), the anticipation of the opportunity of extracting rents reduces the likelihood that subjects with the average dishonesty (for which the standardized measure is equal to zero) choose the public contract in 10 percentage points (coefficient $\beta_{1}$ in equation 2). Instead, the anticipation of graft opportunities increases the probability of choosing the public contract for subjects one standard deviation more dishonest than the mean in 1.4 percentage points ( graft opportunities on the probability that more dishonest subjects self-select into the public contract relative to subjects with the average dishonesty is an increase of 11 percentage points $\left(\beta_{3}\right)$.

Column 4 shows that this pattern is driven by the cream of the dishonest. We replace the standardized reported dice number by a dummy that captures the report of an unusually high number and find that subjects who are not big cheaters are 17 percentage points less likely to choose the public contract when rents can be extracted. This is equivalent to 53 
percent of the control group mean. Instead, the anticipation of graft opportunities increases the probability of choosing the public contract for subjects above the $99^{\text {th }}$ percentile of cheating in 6.3 percentage points. Thus, the differential effect of graft opportunities on the probability that top dishonest subjects self-select into the public contract relative to the rest of the subjects is an in increase in 23 percentage points (equivalent to almost 75 percent of the control mean).

Column 5 shows the last piece of supporting evidence for the compositional effect of rent extraction opportunities in terms of the underlying integrity. Relative to the first tercile, only subjects in the third tercile of the empirical distribution of the reported points of the dice task are more likely to choose the public contract when it they anticipate that rents can be extracted.

Taken together, the evidence consistently shows that opportunities for graft deteriorate the pool of individuals who select the public contract. We interpret these findings as supporting Bénabou and Tirole (2011)'s theory of moral behavior in which reputation costs affects the composition of social organizations. In our case, honest subjects anticipate that being part of a corrupt environment would entail some sort of moral cost for them 11

Figure 3 complements Table 2 with suggestive visual evidence. First, Panel A shows that our measure of dishonesty is balanced between those who were offered the cash-based public contract (solid line) and the token-based one (dashed line). As expected given the randomization, these distributions overlap almost completely. However, Panel B illustrates the effect of introducing graft opportunities on the honesty of those who choose the public contract. The thin solid line is the distribution of reported dice totals over all subjects in our experiment, which is presented as a benchmark. The dashed line is the distribution of those who chose the public contract in the token-based version (that had no graft opportunities). This distribution is quite similar to the benchmark but slightly displaced to the left, signaling a very small improvement in selection in terms of honesty. On the other hand, the distribution for those who choose the cash-based public contract (thick solid line) is flatter, with much more mass toward higher values, indicating a clearly worse composition of this group in terms of honesty.

\footnotetext{
${ }^{11}$ We also explore whether the introduction of graft opportunities changed the composition of the subjects who chose the public contract in other dimensions (results available upon request). To do this, we estimated equation 2 by substituting our dishonesty measure with variables capturing other relevant attributes. We found no evidence of heterogeneous responses along risk attitudes or pro-sociality, as captured by our validated instruments. Out of the Big Five personality traits, we only found something with the openness measure: higher values of the openness index are associated with higher rejection rates of the cash-based version of the public contract. However these results do not correct standard errors for multiple hypothesis testing.
} 


\subsection{Allocation of the monetary fund and graft}

Importantly, our setting also allows us to study actual graft. If the opportunity to extract rents affects the decision of individuals regarding contract choice, we would expect to observe individuals cashing in on those opportunities. Table 3 reports our findings regarding the effect of the cash-based public contract on the allocation decisions of the NGOs monetary fund, and specifically on measures of graft in the extensive and in the intensive margins. Recall that, in this table, we restrict our sample to subjects from groups G1 and G2, who chose the public contract.

Columns 1 and 2 focus on the proportion of subjects that kept at least part of the fund (extensive margin) and Columns 3 and 4 on the share kept (intensive margin). Further, even columns control for the reported points in the dice tasks. We find that taking the public contract under the cash-based task increases the probability of keeping part of the fund by 66 percentage points from a baseline of 4.8 percent in the control group. Because tokens in the latter have no value outside the lab, we interpret this coefficient as actual graft. Moreover, this point estimate is very robust to controlling for our incentivized measure of the subjects underlying honesty, which in turn exacerbates graft. Indeed, an increase of one standard deviation in reported dice points raises the likelihood of an incomplete allocation by 6.7 percentage points (Column 2).

Something similar occurs with the share of the fund that is not allocated, which goes from 3 percent to 45 [43] percent when cash is introduced (Column 3 [4]). In addition, an increase of one standard deviation in reported dice points increases the share of the fund that is kept by the subject in 7.8 percentage points (Column 4).

\subsection{Mechanisms: selection vs. incentives}

The previous set of results shows the cash-based version of the public contract leads to graft. This can be a result of either: i) the selection of worse individuals into the cash-based contract or ii) an incentives channel net of the selection effect (or both). We have already established that offering a cash-based contract leads to worse selection in terms of honesty (Table 2), and that dishonesty also predicts graft both in the extensive and in the intensive margin (Table 3). Hence, there are very strong clues that the selection channel has empricial relevance in explaining the observed graft. However, the results from Table 3 do not allow us to separate selection from incentives 12

\footnotetext{
${ }^{12}$ Recall that in those regressions we focused on subjects from groups G1 and G2, and subjects in those two groups both self-selected differently (they were offered different versions of the contract) and also faced different incentives (they undertook different versions of the contract).
} 
Instead, we can do this by exploiting the second randomization embedded in our experiment: individuals in group G3 were offered the token-based version of the public contract, but (if they chose it) they were randomly reassigned to the cash-based task of the contract. This double randomization strategy provides us with observations corresponding to subjects who self-selected into one version of the contract but who actually ended up facing different incentives. Using this variation we estimate equation 4 for all individuals who play the public contract.

The results are reported on Table 4. By and large, they suggest that the observed graft comes from selection. Indeed, those who self-select into the cash-based version of the public contract are 60 percentage points more likely to make an incomplete allocation of the monetary fund, and the share they allocate is on average 40 percentage points smaller. Instead, controlling for the selection channel, the pure incentives effect captured by the Cash-based Played dummy is effectively (both statistically and economically) 0.

This result can also be visualized in Figure 4 where we plot the mean of the fund allocation variables by experimental group. The comparison between the first and third groups captures the pure incentive effect, as individuals who undertake the task of the public contract in those two groups are selected under the same conditions but differ in the task version they ultimately carry out. As reported on the Figure, both the share of incomplete allocations (extensive-margin graft) and share of the NGOs fund kept (intensive margin) are higher for the group playing with cash (9.5 against 4.8 and 5.4 against 3.4, respectively). However, the differences are small and insignificant. Clearly, the significant increase in graft comes from group G2, where the selection channel is activated.

These results eloquently suggest that introducing graft opportunities in a job significantly translates into actual graft taking place, but mostly because individuals with high dishonesty levels self-select disproportionately into that contract. This has clear policy implications that we discuss below. Yet, our finding that there are no important incentive effects must be qualified. We cannot rule out that the importance of incentives is heterogeneous across individuals: for example, more dishonest people could be more responsive to changes in rules that facilitate rent extraction. Our result is that changes in incentives do not lead to important behavioral responses among those who self-select into a contract with no opportunities to extract rents. This suggests that a good selection (in terms of honesty) can mitigate the risks of rule changes that create opportunities for fraud or corruption. 


\section{Conclusions}

This paper provides the first causal estimates on the effect of graft opportunities on the integrity of those who self-select to a specific job or task. Our results highlight that corruption opportunities might not just attract the dishonest but also repel the honest, perhaps because of the reputation or moral costs of being in a corrupt environment. Additionally, our double randomization design allows us to study the contributions of the selection and pure incentives channels to explain graft. We find that selection explains the bulk of graft in this context.

Our experiment informs personnel policies in the public sector. A recurring debate in public sector management pertains to trade-offs associated with increasing officials' discretionary powers. On one hand, doing so increases bureaucracies' agility in responding to contingencies; on the other hand, it can increase the risk of corruption (see Gallego et al. (2020) for recent evidence of the latter in the context of the public response to the COVID-19 pandemic). In our experiment, we study a policy change (the use of cash instead of tokens) that creates opportunities for graft without affecting individuals' ability to carry out the task at hand. This allows us to isolate the pure effect of increasing corruption risks. Our results serve as a warning: policies that facilitate rent extraction do lead to more corruption, especially through self-selection among more dishonest individuals. However, most public administration policies that increase discretion (and create opportunities for malfeasance) also increase the flexibility of individuals to complete tasks, and thus it is important to asses how the corruption costs compare to the benefits of that additional flexibility.

Two policy implications emerge from this. First, it is important to consider potential effects on selection when designing rules and incentives in an organization. Second, improving

public sector recruitment practices should be a focal point of reform, especially where there are high levels of corruption.

Finally, our experiment sheds light on one reason why corruption is so persistent. Organizations where rent extraction is possible disproportionately attract dishonest people, which translates into higher levels of corruption and reinforces these organizations' poor reputations. In short: corruption begets corruption. To break this vicious cycle, policies centered on improving the composition of organizations can be a promising path for reform. 


\section{References}

Abbink, K. And D. Serra (2012): "Chapter 4 Anticorruption Policies: Lessons from the Lab," Research in Experimental Economics, 15, 77-115.

Ashraf, N., O. Bandiera, And S. LeE (2018): "Losing Prosociality in the Quest for Talent? Sorting, Selection, and Productivity in the Delivery of Public Services," LSE Research Online Documents on Economics 88175, London School of Economics and Political Science, LSE Library.

Banerjee, R., T. Baul, and T. Rosenblat (2015): "On Self Selection of the Corrupt into the Public Sector," Economics Letters, 127, 43 - 46.

Barfort, S., N. A. Harmon, F. Huorth, And A. L. Olsen (2019): "Sustaining Honesty in Public Service: The Role of Selection," American Economic Journal: Economic Policy, 11, 96-123.

BÉnabou, R. And J. Tirole (2011): "Identity, morals, and taboos: Beliefs as assets," The Quarterly Journal of Economics, 126, 805-855.

Besley, T. (2005): "Political Selection," Journal of Economic Perspectives, 19, 43-60.

Dal Bo, E., F. Finan, And M. A. Rossi (2013): "Strengthening State Capabilities: The Role of Financial Incentives in the Call to Public Service," The Quarterly Journal of Economics, 128, 1169-1218.

Deserranno, E. (2019): "Financial Incentives as Signals: Experimental Evidence from the Recruitment of Village Promoters in Uganda," American Economic Journal: Applied Economics, 11, 277-317.

Ferraz, C. AND F. FinAn (2009): "Motivating politicians: The impacts of monetary incentives on quality and performance," Tech. rep., National Bureau of Economic Research.

Finan, F., B. Olken, And R. Pande (2017): "Chapter 6 - The Personnel Economics of the Developing State," in Handbook of Economic Field Experiments, ed. by A. V. Banerjee and E. Duflo, North-Holland, vol. 2 of Handbook of Economic Field Experiments, 467 514.

Fischbacher, U. And F. Föllmi-Heusi (2013): "Lies In Disguise: An Experimental Study On Cheating," Journal of the European Economic Association, 11, 525-547. 
Gallego, J. A., M. Prem, and J. F. Vargas (2020): "Corruption in the Times of Pandemia," Available at SSRN 3600572.

Hanna, R. And S.-Y. Wang (2017): "Dishonesty and Selection into Public Service: Evidence from India," American Economic Journal: Economic Policy, 9, 262-90.

Karlan, D. And J. Zinman (2009): "Observing Unobservables: Identifying Information Asymmetries With a Consumer Credit Field Experiment," Econometrica, 77, 1993-2008.

Olken, B. A. (2007): "Monitoring Corruption: Evidence from a Field Experiment in Indonesia," Journal of Political Economy, 115, 200-249.

Olken, B. A. And R. Pande (2012): "Corruption in Developing Countries," Annual Review of Economics, 4, 479-509.

Svensson, J. (2005): "Eight Questions about Corruption," Journal of Economic Perspectives, 19, 19-42. 
Figure 1: Description of experimental sessions

\begin{tabular}{|c|c|c|c|c|c|c|c|}
\hline & $\begin{array}{l}\text { Stage 1: Individua } \\
\text { information }\end{array}$ & $\begin{array}{r}\text { Stage 2: } \\
\text { chc }\end{array}$ & ontrac & & & $\begin{array}{c}\text { Stage 3: } \\
\text { Reassignment }\end{array}$ & $\begin{array}{l}\text { Stage 4: play and } \\
\text { payments }\end{array}$ \\
\hline $\begin{array}{l}\text { G1 sessions } \\
\mathrm{N}=136\end{array}$ & & $\begin{array}{l}\text { Choice between } \\
\text { contracts }\end{array}$ & $\longrightarrow$ & $\begin{array}{l}\text { Private } \\
\text { Token-based }\end{array}$ & $\begin{array}{l}\rightarrow \\
\rightarrow\end{array}$ & $\begin{array}{l}\text { Private } \\
\text { Token-based }\end{array}$ & \\
\hline $\begin{array}{l}\text { G2 sessions } \\
\quad \mathrm{N}=131\end{array}$ & $\begin{array}{l}\text { Survey and } \\
\text { dice game }\end{array}$ & $\begin{array}{c}\text { Choice between } \\
\text { contracts }\end{array}$ & $\longrightarrow$ & $\begin{array}{l}\text { Private } \\
\text { Cash-based }\end{array}$ & $\begin{array}{l}\rightarrow \\
\rightarrow\end{array}$ & $\begin{array}{l}\text { Private } \\
\text { Cash-based }\end{array}$ & $\rightarrow \begin{array}{l}\text { Play and receive } \\
\text { payment }\end{array}$ \\
\hline $\begin{array}{l}\text { G3 sessions } \\
\quad \mathrm{N}=131\end{array}$ & & $\begin{array}{c}\text { Choice between } \\
\text { contracts }\end{array}$ & $\longrightarrow$ & $\begin{array}{l}\text { Private } \\
\text { Token-based }\end{array}$ & $\begin{array}{l}\longrightarrow \\
\rightarrow\end{array}$ & $\begin{array}{l}\text { Private } \\
\text { Cash-based }\end{array}$ & \\
\hline
\end{tabular}


Figure 2: Dice points: Simulated and experimental distributions

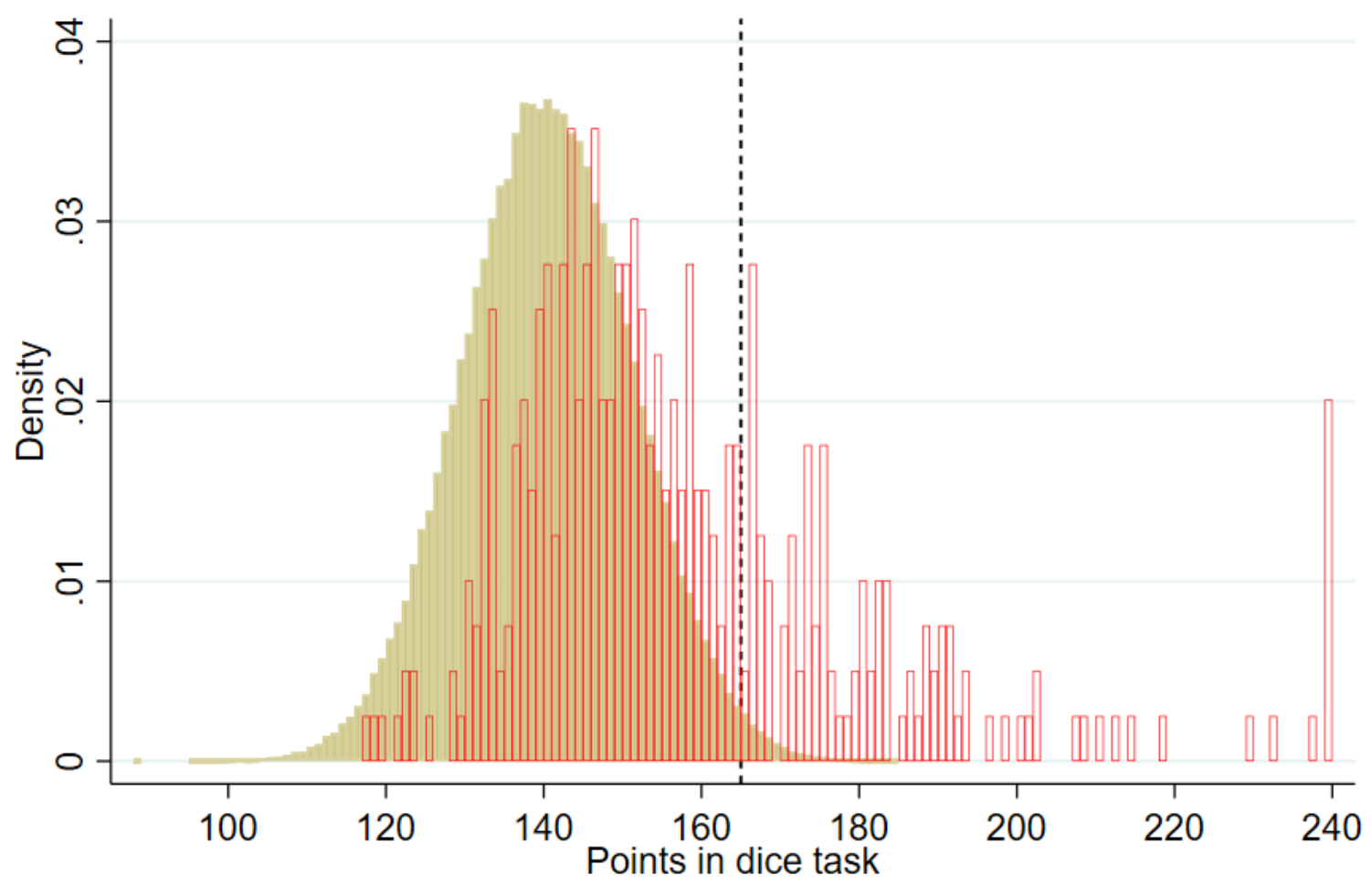

Simulated Distribution

Experimental Distribution

Notes: The figure shows both the experimental distribution of points in the dice task and the simulated distribution. The dashed vertical line shows the value corresponding to the 99th percentile of the simulated distribution. 


\section{Figure 3: Distribution of dishonesty measure}
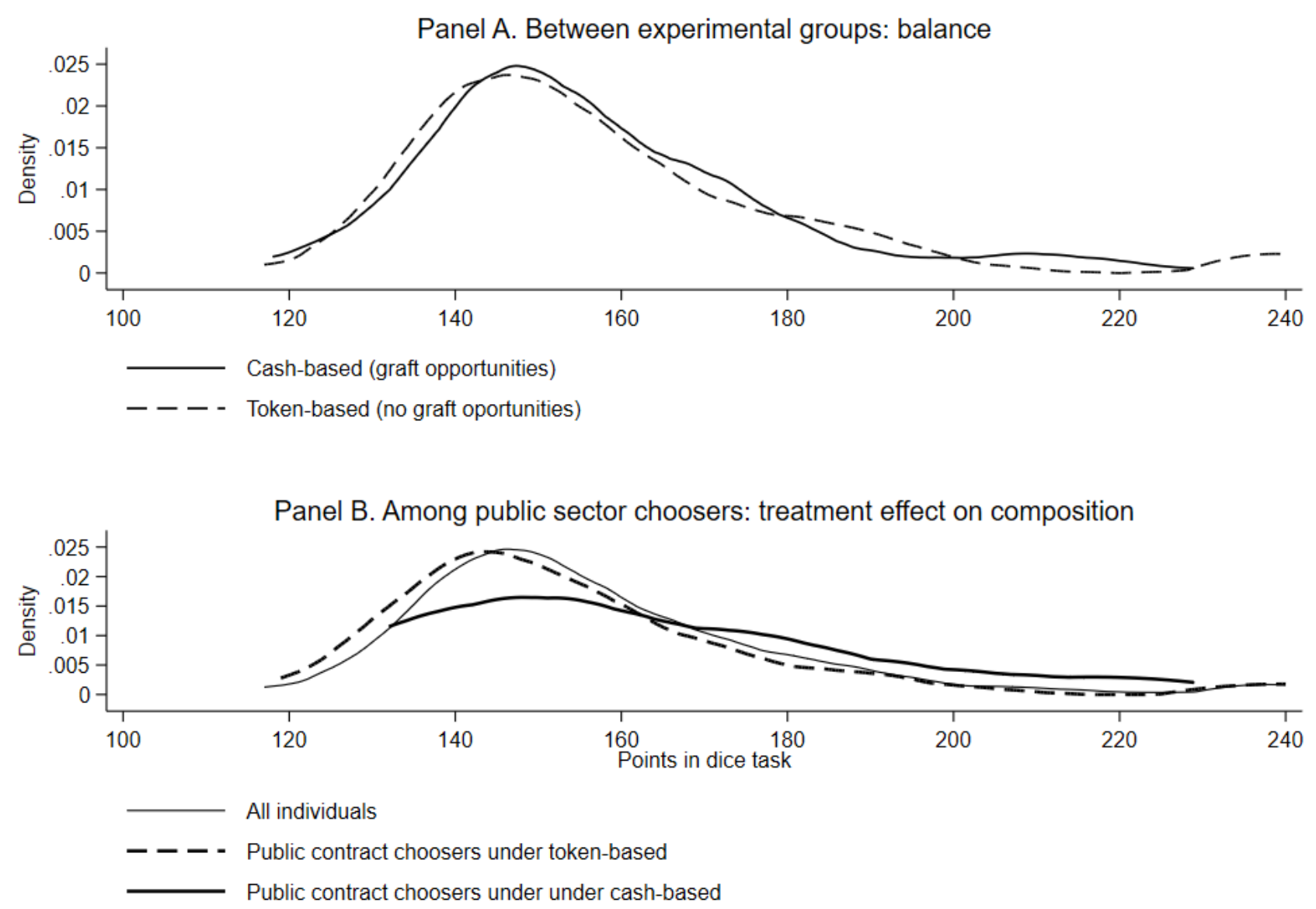

Notes: Panel A shows kernel density estimates of total dice points for experimental groups G2 (solid line) and G1-G3 (dashed line). Panel B shows kernel density estimates of total dice points for the full sample (thin solid line), those who choose the public contract in experimental group G2 (thick solid line), and those who choose the public contract in experimental groups G1-G3 (dashed line). 


\section{Figure 4: Donation by experimental groups}

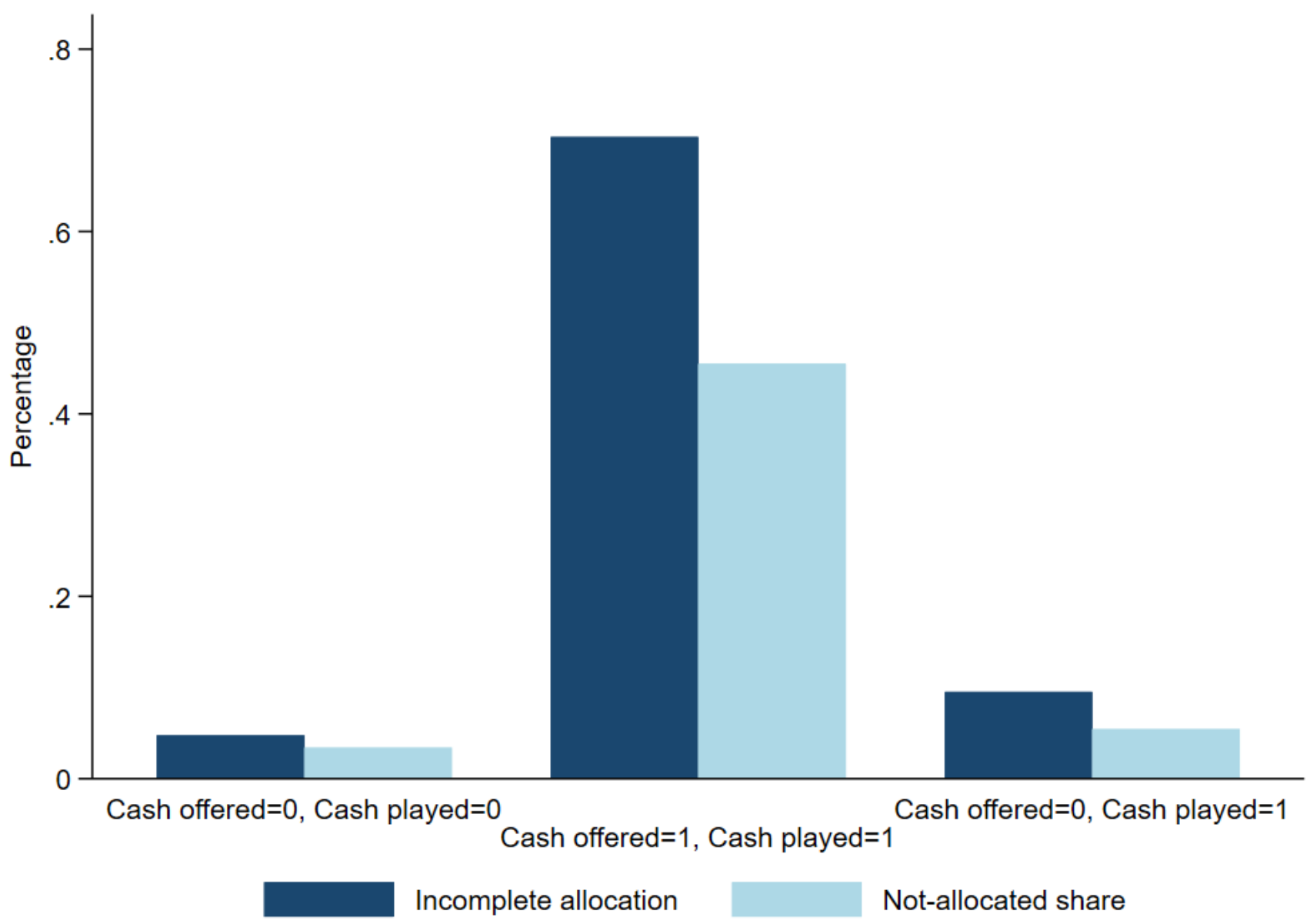

Notes: The figure reports the monetary fund allocation measures by experimental group. Dark blue bars show the percentage of participants who do not fully allocate the fund among the NGOs, while light blue bars show the average share of the fund not allocated. 


\section{Table 1: Summary statistics and balance of covariates between groups}

\begin{tabular}{|c|c|c|c|}
\hline & $\begin{array}{l}\text { G1 } \\
(1)\end{array}$ & $\begin{array}{l}\text { G1-G2 } \\
(2)\end{array}$ & $\begin{array}{c}\text { G1-G3 } \\
(3)\end{array}$ \\
\hline Female & $\begin{array}{c}0.610 \\
(0.489)\end{array}$ & $\begin{array}{l}-0.023 \\
(0.060)\end{array}$ & $\begin{array}{l}-0.068 \\
(0.061)\end{array}$ \\
\hline Age & $\begin{array}{l}20.434 \\
(1.908)\end{array}$ & $\begin{array}{c}0.062 \\
(0.245)\end{array}$ & $\begin{array}{c}0.062 \\
(0.254)\end{array}$ \\
\hline Quantitative Major & $\begin{array}{c}0.338 \\
(0.475)\end{array}$ & $\begin{array}{l}-0.002 \\
(0.058)\end{array}$ & $\begin{array}{c}0.021 \\
(0.059)\end{array}$ \\
\hline GPA $($ Mean $=0, \mathrm{SD}=1)$ & $\begin{array}{l}-0.005 \\
(0.917)\end{array}$ & $\begin{array}{l}-0.045 \\
(0.120)\end{array}$ & $\begin{array}{l}0.028 \\
(0.114)\end{array}$ \\
\hline High Socioeconomic Stratum & $\begin{array}{c}0.618 \\
(0.488)\end{array}$ & $\begin{array}{l}-0.083 \\
(0.060)\end{array}$ & $\begin{array}{l}-0.106^{*} \\
(0.061)\end{array}$ \\
\hline Preference for Public Sector Job & $\begin{array}{c}0.566 \\
(0.497)\end{array}$ & $\begin{array}{l}-0.017 \\
(0.061)\end{array}$ & $\begin{array}{l}-0.009 \\
(0.061)\end{array}$ \\
\hline Points in dice task & $\begin{array}{l}158.294 \\
(24.660)\end{array}$ & $\begin{array}{l}-1.744 \\
(2.892)\end{array}$ & $\begin{array}{l}-1.836 \\
(2.779)\end{array}$ \\
\hline High points in dice task ( $\mathrm{p} \geq 99$ of simulated distribution) & $\begin{array}{c}0.301 \\
(0.461)\end{array}$ & $\begin{array}{l}-0.057 \\
(0.055)\end{array}$ & $\begin{array}{l}-0.019 \\
(0.056)\end{array}$ \\
\hline Declares bribe is justified & $\begin{array}{c}0.103 \\
(0.305)\end{array}$ & $\begin{array}{l}-0.034 \\
(0.034)\end{array}$ & $\begin{array}{c}0.019 \\
(0.039)\end{array}$ \\
\hline Risk Preference $($ Mean $=0, \mathrm{SD}=1)$ & $\begin{array}{c}0.026 \\
(1.031)\end{array}$ & $\begin{array}{c}0.056 \\
(0.122)\end{array}$ & $\begin{array}{l}-0.114 \\
(0.127)\end{array}$ \\
\hline Prosociality Index $($ Mean $=0, S D=1)$ & $\begin{array}{c}0.017 \\
(1.089)\end{array}$ & $\begin{array}{c}0.027 \\
(0.126)\end{array}$ & $\begin{array}{l}-0.146 \\
(0.123)\end{array}$ \\
\hline Big Five, Extraversion $($ Mean $=0, S D=1)$ & $\begin{array}{c}0.013 \\
(1.034)\end{array}$ & $\begin{array}{c}0.018 \\
(0.122)\end{array}$ & $\begin{array}{l}-0.158 \\
(0.125)\end{array}$ \\
\hline Big Five, Agreeableness (Mean $=0, \mathrm{SD}=1)$ & $\begin{array}{c}-0.016 \\
(1.046)\end{array}$ & $\begin{array}{l}-0.009 \\
(0.128)\end{array}$ & $\begin{array}{l}-0.066 \\
(0.118)\end{array}$ \\
\hline Big Five, Conscientiousness (Mean $=0, \mathrm{SD}=1)$ & $\begin{array}{c}0.061 \\
(0.970)\end{array}$ & $\begin{array}{l}-0.013 \\
(0.119)\end{array}$ & $\begin{array}{l}-0.114 \\
(0.122)\end{array}$ \\
\hline Big Five, Neuroticism (Mean=0, $\mathrm{SD}=1$ ) & $\begin{array}{c}0.009 \\
(1.075)\end{array}$ & $\begin{array}{c}0.017 \\
(0.126)\end{array}$ & $\begin{array}{c}-0.032 \\
(0.128)\end{array}$ \\
\hline Big Five, Openness (Mean $=0, \mathrm{SD}=1)$ & $\begin{array}{l}-0.035 \\
(0.898)\end{array}$ & $\begin{array}{c}0.061 \\
(0.117)\end{array}$ & $\begin{array}{c}0.086 \\
(0.122)\end{array}$ \\
\hline Observations & 136 & 267 & 267 \\
\hline
\end{tabular}

Notes: The table shows summary statistics and the balance of covariates between experimental groups. Column (1) presents the mean and standard deviation of each variable for individuals in G1 sessions. Columns (2) and (3) show the mean differences for each variable between individuals in G1 sessions with respect to those in G2 and G3 sessions, respectively, and the corresponding t-statistics in parentheses. * significant at $10 \%$, ** significant at $5 \%, * * *$ significant at $1 \%$. The last row shows the number of observations used for the calculation of each column's statistics: in Column (1) this corresponds to the size of group G1, while in Columns (2) and (3) it indicates the sizes of groups G1 and G2, and G1 and G3, respectively. GPA = grade point average. 
Table 2: Contract choice

\begin{tabular}{|c|c|c|c|c|c|}
\hline & \multicolumn{5}{|c|}{ Dependent variable: Public contract choice } \\
\hline & $(1)$ & $(2)$ & $(3)$ & $(4)$ & $(5)$ \\
\hline Cash-based & $\begin{array}{l}-0.102^{* *} \\
(0.045)\end{array}$ & $\begin{array}{l}-0.100^{* *} \\
(0.048)\end{array}$ & $\begin{array}{l}-0.100^{* *} \\
(0.048)\end{array}$ & $\begin{array}{l}-0.167^{* * *} \\
(0.053)\end{array}$ & $\begin{array}{l}-0.179^{* *} \\
(0.085)\end{array}$ \\
\hline Dice points & & $\begin{array}{l}0.003 \\
(0.024)\end{array}$ & $\begin{array}{l}-0.027 \\
(0.027)\end{array}$ & & \\
\hline Cash-based x Dice points & & & $\begin{array}{l}0.114^{* *} \\
(0.053)\end{array}$ & & \\
\hline Unlikely dice points & & & & $\begin{array}{l}-0.065 \\
(0.064)\end{array}$ & \\
\hline Cash-based x Unlikely dice points & & & & $\begin{array}{l}0.230^{* *} \\
(0.111)\end{array}$ & \\
\hline Tertile 2 , dice & & & & & $\begin{array}{l}-0.145^{* *} \\
(0.069)\end{array}$ \\
\hline Tertile 3, dice & & & & & $\begin{array}{l}-0.115 \\
(0.073)\end{array}$ \\
\hline Cash-based $\mathrm{x}$ tertile 2 & & & & & $\begin{array}{l}0.017 \\
(0.110)\end{array}$ \\
\hline Cash-based $\mathrm{x}$ tertile 3 & & & & & $\begin{array}{l}0.213^{*} \\
(0.121)\end{array}$ \\
\hline Controls & & & & & \\
\hline Stratification varaibles & Yes & Yes & Yes & Yes & Yes \\
\hline All controls & No & Yes & Yes & Yes & Yes \\
\hline Mean of dependent variable (control) & 0.315 & 0.315 & 0.315 & 0.315 & 0.378 \\
\hline Observations & 398 & 398 & 398 & 398 & 398 \\
\hline R-squared & 0.040 & 0.090 & 0.102 & 0.084 & 0.116 \\
\hline
\end{tabular}

Notes: The table presents the ordinary least squares (OLS) estimates of the effects of introducing rent extraction opportunities in the public contract on the proportion and type of individuals who choose it. The dependent variable is a binary indicator that takes the value 1 if the individual chooses the public contract and 0 otherwise. The treatment variable, Cash-based, is a binary indicator that takes the value 1 for participants in group G2 (i.e., those who are offered the cash-based public contract) and 0 for participants in groups G1 and G3 (i.e., those who are offered the token-based public contract). Columns (1) and (2) show the baseline results. Column (3) shows the results when the treatment variable is interacted with the total number of points reported by participants in the dice game. Column (4) shows the results when the treatment variable is interacted with an indicator of having reported total dice points above the 99th percentile of the theoretical distribution. Column (5) shows the results when the treatment variable is interacted with a categorical variable with the tertiles of the distribution of reported dice points. Column (1) controls for the stratification variables: gender, a dummy for preference for public sector positions, and a dummy for quantitative major. Columns (2) to (5) also control for age, GPA, socioeconomic status, risk preference, prosociality, and the Big Five personality traits. Robust standard errors are in parentheses. ${ }^{*}$ significant at $10 \%,{ }^{* *}$ significant at $5 \%,{ }^{* * *}$ significant at $1 \%$. 


\section{Table 3: Graft: Differences in monetary fund allocation by type of contract}

\begin{tabular}{|c|c|c|c|c|}
\hline & \multicolumn{2}{|c|}{ Incomplete allocation } & \multicolumn{2}{|c|}{ Not-allocated share } \\
\hline & $(1)$ & $(2)$ & $(3)$ & $(4)$ \\
\hline $\begin{array}{l}\text { Cash-based } \\
\text { Dice points }\end{array}$ & $\begin{array}{l}0.656^{* * *} \\
(0.095)\end{array}$ & $\begin{array}{l}0.635^{* * *} \\
(0.097) \\
0.067^{* *} \\
(0.032)\end{array}$ & $\begin{array}{l}0.421^{* * *} \\
(0.079)\end{array}$ & $\begin{array}{l}0.397^{* * *} \\
(0.075) \\
0.078^{* *} \\
(0.033)\end{array}$ \\
\hline $\begin{array}{l}\text { Mean of dependent variable } \\
\text { (Comparison group) }\end{array}$ & 0.048 & 0.048 & 0.034 & 0.034 \\
\hline Observations & 69 & 69 & 69 & 69 \\
\hline R-squared & 0.484 & 0.512 & 0.366 & 0.434 \\
\hline
\end{tabular}

Notes: The table presents the OLS estimates of the difference in the fund allocation measures by type of public contract offered. The dependent variable in Columns (1) and (2) is a binary indicator that takes the value 1 if individuals did not fully allocate the fund among the NGOs and 0 otherwise, while in Columns (3) and (4), it is the share of the fund that is not allocated. The treatment variable, Cash-based, is a binary indicator that takes the value 1 for participants in group G2 (i.e., those who are offered the cash-based public contract) and 0 for participants in group G1 (i.e., those who are offered the token-based public contract). Only individuals who choose the public contract in experimental groups G1 and G2 are included in the regressions, since the variable cash-based is not well defined for those in group G3 (they did not play the same version of the contract that they chose). Robust standard errors are in parentheses. ${ }^{*}$ significant at $10 \%,{ }^{* *}$ significant at $5 \%,{ }^{* * *}$ significant at $1 \%$. 


\section{Table 4: Separating selection and incentive effects}

\begin{tabular}{|c|c|c|c|c|c|c|}
\hline & \multicolumn{3}{|c|}{ Incomplete allocation } & \multicolumn{3}{|c|}{ Not-allocated share } \\
\hline & $(1)$ & $(2)$ & $(3)$ & $(4)$ & $(5)$ & $(6)$ \\
\hline Cash-based Offered & $\begin{array}{l}0.608^{* * *} \\
(0.100)\end{array}$ & $\begin{array}{l}0.606^{* * *} \\
(0.102)\end{array}$ & $\begin{array}{l}0.596^{* * *} \\
(0.102)\end{array}$ & $\begin{array}{l}0.401^{* * *} \\
(0.080)\end{array}$ & $\begin{array}{l}0.377^{* * *} \\
(0.075)\end{array}$ & $\begin{array}{l}0.366^{* * *} \\
(0.071)\end{array}$ \\
\hline Cash-based Played & $\begin{array}{l}0.048 \\
(0.057)\end{array}$ & $\begin{array}{l}0.007 \\
(0.055)\end{array}$ & $\begin{array}{l}0.008 \\
(0.058)\end{array}$ & $\begin{array}{l}0.020 \\
(0.040)\end{array}$ & $\begin{array}{l}0.021 \\
(0.043)\end{array}$ & $\begin{array}{l}0.022 \\
(0.044)\end{array}$ \\
\hline Dice points & & & $\begin{array}{l}0.038 \\
(0.029)\end{array}$ & & & $\begin{array}{l}0.045 \\
(0.027)\end{array}$ \\
\hline Controls & & & & & & \\
\hline Stratification variables & Yes & Yes & Yes & Yes & Yes & Yes \\
\hline All controls & No & Yes & Yes & No & Yes & Yes \\
\hline $\begin{array}{l}\text { Mean of dep. variable } \\
\text { (Comparison group) }\end{array}$ & 0.048 & 0.048 & 0.048 & 0.034 & 0.034 & 0.034 \\
\hline Observations & 111 & 111 & 111 & 111 & 111 & 111 \\
\hline R-squared & 0.424 & 0.550 & 0.558 & 0.344 & 0.474 & 0.496 \\
\hline
\end{tabular}

Notes: The table presents the OLS estimates of the effect of contract offer and contract assignment on measures of monetary fund allocation. The dependent variable in Columns (1) to (3) is a binary indicator that takes the value 1 if individuals did not fully allocate the monetary fund and 0 otherwise, while in Columns (4) to (6), it is the share of the fund that is not allocated. There are two treatment variables: cash-based offered is a binary indicator takes the value 1 for participants in group G2 (i.e., those who are offered the cash-based public contract) and 0 for participants in groups G1 and G3 (i.e., those who are offered the token-based public contract), while Cash-based played is a binary indicator that takes the value 1 for individuals in groups G2 and G3 (i.e., those who played the cash-based public contract either by choice or re-assignment) and 0 for individuals in group G1 (i.e., those who played the token-based public contract). Columns (1) and (4) control for the stratification variables: gender, a dummy for preference for public sector positions, and a dummy for quantitative major. Columns (2), (3), (5), and (6) also control for age, GPA, socioeconomic status, risk preference, prosociality, and the Big Five personality traits. The regressions include individuals who choose the public contract in all experimental groups. Robust standard errors are in parentheses. ${ }^{*}$ significant at $10 \%,{ }^{* *}$ significant at $5 \%,{ }^{* * *}$ significant at $1 \%$. 